\title{
Prevalence, Risk Factors, Awareness, and Treatment and Control of Hypertension in Mafia Island, Tanzania
}

\author{
M. S. Muhamedhussein, ${ }^{1}$ Z. I. Nagri, ${ }^{2}$ and K. P. Manji ${ }^{3}$ \\ ${ }^{1}$ Regency Medical Center, P.O. Box 2029, Dar es Salaam, Tanzania \\ ${ }^{2}$ Shree Hindu Mandal Hospital, P.O. Box 581, Dar es Salaam, Tanzania \\ ${ }^{3}$ Department of Pediatrics and Child health, Muhimbili University of Health and Allied Sciences, \\ P.O. Box 65001, Dar es Salaam, Tanzania \\ Correspondence should be addressed to M. S. Muhamedhussein; mohamedshabbir@hotmail.com
}

Received 27 April 2016; Revised 9 June 2016; Accepted 27 June 2016

Academic Editor: Francesco Cappuccio

Copyright (C) 2016 M. S. Muhamedhussein et al. This is an open access article distributed under the Creative Commons Attribution License, which permits unrestricted use, distribution, and reproduction in any medium, provided the original work is properly cited.

\begin{abstract}
Introduction. The prevalence of hypertension in Africa ranges from $29.7 \%$ in Cameroon to $47 \%$ in South Africa. Only $10 \%$ receive treatment in Cameroon while $32 \%$ are on medications in Ghana. Control rates vary from $0.4 \%$ to $16.8 \%$. This study was done to assess prevalence, risk factors, awareness, treatment, and control of hypertension in Mafia Island, Tanzania, which has never been documented before, so that necessary interventions can be undertaken accordingly. Methodology. Data was collected through questionnaires and anthropometric measurements were taken. Descriptive statistics were done and potential correlations were analyzed. Results. Out of 570 adults who were included in the study, 154 (27\%) were aged $41-50$ and the male-to-female ratio was $1: 1.05$. Almost half (49.5\%) of the participants fit into the criteria of hypertension. Out of the 118 participants who were aware of having hypertension, 68 (57.6\%) were currently taking medication. From those taking medication, only $14(20.6 \%)$ had controlled hypertension. Conclusion. This study tried to show the extent of hypertension and find out risk factors which could explain the high prevalence of hypertension. This is very alarming and a dire need to raise awareness through health education, availability of screening, and treating and follow-up should be given priority.
\end{abstract}

\section{Introduction}

Hypertension is a rapidly emerging disease worldwide and contributes highly to morbidity and mortality. Risk factors not only include obesity, sedentary lifestyle, and age but also genetics and environmental factors contribute to it. Hypertension is usually asymptomatic and the patient presents to the hospital with one of the complications especially in developing countries where very minimal importance and minimal resources are allocated to noncommunicable diseases.

A study showed that $80 \%$ of deaths that result from noncommunicable diseases occur in the developing world [1]. Another study has predicted an increase of $80 \%$ in the number of hypertensives by 2025 [2]. Studies from South Africa have shown that obesity and hypertension are the most prevalent cardiovascular risk factor [3]. As a result, the most common presentation with chronic heart failure is due to hypertensive heart disease [4]. By 2030, $85 \%$ of the 23 million cardiovascular deaths projected will be in low and middle income countries [5].

In Cameroon, $29.7 \%$ of all participants in a study had hypertension [6] while it was a staggering $47 \%$ among females in South Africa [7]. Treatment of those who were known to have hypertension was a mere $10 \%$ in Cameroon [8] and 32\% in Ghana [9]. Out of those using medicines, only between $0.4 \%$ and $16.8 \%$ had optimal control $[7,8]$. In another study conducted in Cameroon, $47.5 \%$ of people had hypertension, from which only $31.7 \%$ were aware of their status [10]. A study done in Kilimanjaro showed prevalence of hypertension to be $30 \%$ in males and $28.6 \%$ in females of which under $20 \%$ of the patient with hypertension were aware of their status. Only $10 \%$ were on medication and less than $1 \%$ had optimal controlled blood pressure [8]. 
Health education is extremely vital in health care system, particularly in chronic conditions such as hypertension, which can be prevented, delayed or controlled with the help of medications and lifestyle changes. Developing countries, due to the high burden of infectious diseases, are far behind the ideal health awareness and education in their population. For the government and health care workers to put emphasis on a particular disease or diseases, the burden of that particular disease should be known. This study aimed at providing a baseline so that the governement can allocate its resources according to the need to be able to reduce morbidity and mortality and to improve health of the people.

\section{Methodology}

2.1. Study Design and Setting. This cross-sectional study was done in Mafia Island, Tanzania. Mafia Island is part of the Tanzanian Spice Islands, together with Unguja and Pemba. According to the 2002 Tanzania census, the population of the Mafia District was 40,801 [11]. The economy is based on fishing and subsistence agriculture. Mafia's infrastructure is poor: it has electricity only in the district capital and in Utende, the main tourist area. There are few houses which have running water. The vast majority of Mafia's population is extremely poor. The major cash crop, coconuts, has a declining price on both world and local markets. Mafia has no newspapers, bookshops, or libraries, and people are primarily dependent upon radio for information about the world beyond the East Coast of Africa. However, modern telecommunications are beginning to be available [12].

2.2. Sampling Method and Data Collection. The study used convenience sampling method and achieved a sample size of 570 nonpregnant adults. An eye and medical camp was organized in Mafia Island in October 2011. This was held at a primary school compound in which there was prior notice to the local people to raise awareness of the medical camp. The questionnaire was filled by medical students, medical personnel, and research assistants whereas measurements were done by medical students and medical personnel only. The information on demographics, smoking habits, alcohol consumption, family history of hypertension, and personal medical history (only diagnosis made by a doctor was considered) including drug treatment was collected by using a questionnaire in Kiswahili. The questionnaires were tested within Dar es Salaam before the research. Participants with high blood pressure were considered to be aware of their status if they answered "yes" to the question "Do you suffer from hypertension?" Treatment of hypertension was defined by the use of blood pressure lowering medications.

\subsection{Measurement of Blood Pressure and Anthropometry.} Blood pressure was measured using aneroid sphygmomanometer (RIESTER brand) while the subject was seated and relaxed with their hand at the level of the heart. People who had eaten food, smoked cigarette, or used alcohol within 30 minutes were asked to rest for 30 minutes before measurements were taken. A standard size of cuff was used.
Anthropometric measurements (weight and height) of the sample were taken, body mass index thereafter calculated by using weight $(\mathrm{Kg}) /$ height $(\mathrm{M})^{2}$. Weight was taken using a regular weighing machine after removal of shoes and excess weight in pockets while height was taken using a measuring board resting on the wall. Weight was calculated to nearest $0.5 \mathrm{~kg}$ and height to nearest $1 \mathrm{~cm}$.

2.4. Definition of Terms. Blood pressure was classified according to the Joint National Committee for hypertension (JNC VII). It was classified as normal blood pressure if systolic blood pressure was between 90 and $119 \mathrm{mmHg}$ and diastolic blood pressure was between 60 and $79 \mathrm{mmHg}$, prehypertension (mildly elevated) when systolic blood pressure was $120-139 \mathrm{mmHg}$ and diastolic blood pressure was $80-$ $89 \mathrm{mmHg}$, Stage 1 hypertension (moderately elevated) when systolic blood pressure was between 140 and $159 \mathrm{mmHg}$ and diastolic blood pressure was between 90 and $99 \mathrm{mmHg}$, and Stage 2 hypertension (severely elevated) when systolic blood pressure was more than $160 \mathrm{mmHg}$ and diastolic blood pressure was more than $100 \mathrm{mmHg}$ [13]. Hypertension was considered to be controlled among treated individuals when systolic blood pressure was less than $140 \mathrm{mmHg}$ and diastolic blood pressure was less than $90 \mathrm{mmHg}$.

Body mass index was categorized according to World Health organization and classified as underweight if BMI $<18.5 \mathrm{~kg} / \mathrm{m}^{2}$, normal if it was between $18.5 \mathrm{~kg} / \mathrm{m}^{2}$ and $25.0 \mathrm{~kg} / \mathrm{m}^{2}$, and overweight if it was from $25.1 \mathrm{~kg} / \mathrm{m}^{2}$ to $30 \mathrm{~kg} / \mathrm{m}^{2}$. The participants were categorized as obese when body mass index was between $30.1 \mathrm{~kg} / \mathrm{m}^{2}$ and $40 \mathrm{~kg} / \mathrm{m}^{2}$ and morbidly obese if BMI was more than $40 \mathrm{~kg} / \mathrm{m}^{2}$ [14].

2.5. Statistical Analysis. Descriptive statistics were used to present tables. Data analysis was done from the processed data first by running frequencies, making comparison tables with regard to blood pressure and $p$ value was calculated using two-variable Chi-square test. Univariate analysis of variance was also done. Data was entered and processed in SPSS version 17. In this study, $p$ value of $\leq 0.05$ was considered to be significant.

2.6. Ethical Considerations. Permission to conduct the study was obtained from the school of medicine at Muhimbili University of Health and Allied Sciences (MUHAS). Also, permission was sought from responsible authorities in Mafia Island.

\section{Results}

Twenty-seven percent of the participants were between 41 and 50 years of age. The mean age was 44.53 with standard deviation of 13.92. There were almost equal males and females with $50.9 \%$ of them being females and $49.1 \%$ being males. The majority $(53.3 \%)$ of the participants had primary level education while $28.1 \%$ had no formal education.

Almost a third (32.6\%) of the participants had mildly elevated blood pressure and $24.6 \%$ had moderately elevated 
TABLE 1: Prevalence, risk factors, awareness, and control of blood pressure.

\begin{tabular}{|c|c|c|c|}
\hline Blood pressure & Normotensive & Hypertensive & $p$ value \\
\hline \multicolumn{4}{|l|}{ Gender } \\
\hline Male & $134(47.8 \%)$ & $146(52.2 \%)$ & \multirow{2}{*}{0.210} \\
\hline Female & $154(53.1 \%)$ & $134(46.9 \%)$ & \\
\hline \multicolumn{4}{|l|}{ Age } \\
\hline$<40$ & $150(73.5 \%)$ & $54(26.5 \%)$ & \multirow{3}{*}{$<0.05$} \\
\hline $40-50$ & $78(50.3 \%)$ & $76(49.3 \%)$ & \\
\hline$>50$ & $60(28.3 \%)$ & $152(71.7 \%)$ & \\
\hline \multicolumn{4}{|l|}{ Educational status } \\
\hline No formal education & $54(33.8 \%)$ & $106(66.2 \%)$ & \multirow{4}{*}{$<0.05$} \\
\hline Primary & $162(53.3 \%)$ & $142(46.7 \%)$ & \\
\hline Secondary & $64(68.8 \%)$ & $29(31.2 \%)$ & \\
\hline College & $8(66.7 \%)$ & $4(33.3 \%)$ & \\
\hline \multicolumn{4}{|l|}{ Family history } \\
\hline Yes & $88(44.9 \%)$ & $108(55.1 \%)$ & \multirow{3}{*}{$<0.05$} \\
\hline No & $24(37.5 \%)$ & $40(62.5 \%)$ & \\
\hline Do not know & $176(56.8 \%)$ & $134(43.2 \%)$ & \\
\hline \multicolumn{4}{|l|}{ Awareness } \\
\hline Yes & $34(28.8 \%)$ & $84(71.2 \%)$ & \multirow{3}{*}{$<0.05$} \\
\hline No & $22(64.7 \%)$ & $12(35.3 \%)$ & \\
\hline Do not know & $232(55.5 \%)$ & $186(44.5 \%)$ & \\
\hline \multicolumn{4}{|l|}{$B M I$} \\
\hline Underweight & $22(84.6 \%)$ & $4(15.4 \%)$ & \multirow{5}{*}{$<0.05$} \\
\hline Normal & $152(59.8 \%)$ & $102(40.2 \%)$ & \\
\hline Overweight & $78(43.8 \%)$ & $100(56.2 \%)$ & \\
\hline Obese & $36(34.5 \%)$ & $68(65.4 \%)$ & \\
\hline Morbidly obese & $0(0 \%)$ & $8(100 \%)$ & \\
\hline \multicolumn{4}{|l|}{ Smoking } \\
\hline Yes & $34(73.9 \%)$ & $12(26.1 \%)$ & \multirow{2}{*}{$<0.05$} \\
\hline No & $254(48.4 \%)$ & $270(51.5 \%)$ & \\
\hline \multicolumn{4}{|l|}{ Alcohol } \\
\hline Yes & $18(50 \%)$ & $18(50 \%)$ & \multirow{2}{*}{0.948} \\
\hline No & $270(50.6 \%)$ & $264(49.5 \%)$ & \\
\hline \multicolumn{4}{|l|}{ Control BP } \\
\hline Medication & $14(20.6 \%)$ & $54(79.4 \%)$ & \multirow{2}{*}{0.21} \\
\hline No medication & $20(40 \%)$ & $30(60 \%)$ & \\
\hline
\end{tabular}

BP while $24.9 \%$ of the participants had severely high blood pressure (Table 1) and hence that makes a total of $49.5 \%$ who qualify to be called hypertensives according to American Heart Association.

Out of the 570 participants, $46(8.1 \%)$ were current smokers from which 24 smoke $<5$ cigarettes a day, 18 smoke between 5 and 15 cigarettes a day, and 4 smoke more than 15 cigarettes a day. A few (6.3\%) of the participants consume alcohol. Out of these, $77.8 \%$ (28) consume alcohol less than 2 times a week, 16.7\% (6) consume alcohol between 2 and 4 times a week, and 5.6\% (2) consume alcohol more than 4 times a week.

Out of the 118 patients who were aware of having hypertension, only $68(57.6 \%)$ were currently taking medication.
The rest were not taking medications mainly due to unavailability of antihypertensives or unaffordability of these drugs (Table 1). Out of those taking medicines, only $14(20.6 \%)$ had controlled blood pressure while 54 (79.4\%) had uncontrolled hypertension.

\section{Discussion}

4.1. Prevalence and Awareness. In this initial screening, moderate to severe high blood pressure was seen among $49.5 \%$ of the participants. In males, high blood pressure was seen among $52.1 \%$ (146) participants while in females it was at $46.9 \%$ (136) though this was not statistically significant ( $p$ value 0.21 ). Compared to the prevalence of hypertension in Africa, that ranges from $29.7 \%$ in Cameroon to $47 \%$ in South Africa and the studies done in Dar es Salaam and Kilimanjaro in which prevalence of hypertension was shown to be $30 \%$ males and $28.6 \%$ females, this is alarmingly high. Despite the limitation of few observations, the cut-off of $140 \mathrm{mmHg}$ systolic pressure and $90 \mathrm{mmHg}$ diastolic pressure is still very crucial.

Of those who had hypertension, only $26.6 \%$ were aware of their diagnosis which is a bit higher compared to the study in Dar es Salaam that showed just under $20 \%$ of hypertensive subjects were aware of their diagnosis. This may be higher but it is still very low compared to the ideal situation.

4.2. Risk Factors. The reason behind this alarming prevalence could be not only the sedentary lifestyle in Mafia Island, diet that includes large amount of salt and fish, but also the low level of education and poor and substandard health facilities. In analyzing the relation between high blood pressure and level of education, it was very significant ( $p$ value $<0.05$ ). This fact can be reflected by a very high percentage $(73.3 \%)$ of the participants who did not know if they had hypertension or not (they had never measured). This was particularly disturbing since male and female participants were almost equal and monitoring blood pressure in pregnant women is mandatory. Two-thirds (194 of the 290) of the women had never got their blood pressure measured.

Participants who were underweight had prevalence of high blood pressure at $15.4 \%$ while those who had normal BMI had high blood pressure prevalence of $40.2 \%$. Hypertension was seen in $56.2 \%$ of overweight people and $65.3 \%$ of obese participants. All morbidly obese individuals had high blood pressure. The relation between BMI and high blood pressure was also very significant $(p$ value $<0.05)$.

High blood pressure was almost only (95\%) seen in participants above 31 years. Analysis showed there was very significant relation between age and high blood pressure $(p$ value $<0.05)$. High blood pressure was seen among $26.1 \%$ of smokers and $51.5 \%$ of nonsmokers. The relation between smoking and high blood pressure was very significant $(p$ value $<0.05)$. The blood pressure was elevated in $49.9 \%$ of people who used alcohol and $49.3 \%$ of those who did not use alcohol. This was not significant ( $p$ value 0.948 ). There was also positive corelation between family history and high blood pressure $(p$ value $<0.05)$. The reason of participants 
being unaware would be a wide variety: from ignorance, not having right information, poor health care seeking behaviors, and unavailability of resources.

4.3. Treatment and Control. Out of these 118 patients who were aware of having hypertension, 68 (57.6\%) were currently taking medication. This was very high compared to the study that showed $10 \%$ receive treatment in Cameroon while $32 \%$ are on medications in Ghana and also the Dar es Salaam study that showed approximately $10 \%$ reported receiving treatment. Out of the 118 participants who were aware of having hypertension, only $34(28.8 \%)$ had controlled blood pressure (systolic blood pressure $<140 \mathrm{mmHg}$ and diastolic blood pressure less than $90 \mathrm{mmHg}$ ). Twenty-four (20.3\%) had systolic blood pressure between 140 and $160 \mathrm{mmHg}$ and diastolic blood pressure between 90 and $99 \mathrm{mmHg}$ while $50.8 \%$ had severely high blood pressure (systolic pressure $>160 \mathrm{mmHg}$ and diastolic pressure more than $100 \mathrm{mmHg}$ ). This may be due to various reasons, among which the most likely would be unavailability of medications which was a complaint that was very often received during the research data collection. Noncompliance of the medicines could also contribute to the poor control and this can be associated with level of education. Out of those hypertensives using medications, only $20.7 \%$ had optimal and controlled blood pressure whilst the majority $(79.3 \%)$ had uncontrolled blood pressure. In comparison, $60 \%$ of hypertensives who were not taking medications regularly had controlled blood pressure. However, this was statistically insignificant ( $p$ value 0.21 ). This can also be explained by poor adherence to medications or irregular intake. The potential of myocardial infarction, stroke, and poor quality of life reflected from this statistics is very high. Other contributing factors may be lack of physical activity, unhealthy diet, poor awareness, and suboptimal facilities. In verbal discussions with the participants, it was noted that in Mafia there were significant number of adults with stroke but they were treated at home with alternative medications.

4.4. Potential Limitations and Strengths of Our Study. Participants were those who attended the eye and medical camp that was well publicized. Only patients who could come by themselves were included in the study, while those sick and debilitated people could not make it. Therefore, those with complications of hypertension and diabetes mellitus were not included; thus, there was selection bias. It remains, however, that participants in the study could still differ from the general population by being more or less health conscious and having less severe disease, for example, which could affect some parameters in the study.

The study used a cross-sectional design, which precludes any causality inference.

Diagnosis of hypertension was based on blood pressure measurements during a single encounter, which is variant with guidelines recommendations for hypertension diagnosis using two measurements recorded on three separate occasions [15]. This may have overestimated the prevalence of hypertension and underestimated the level of blood pressure control. This, however, would not affect comparisons with previous epidemiological studies that have used similar measurement methodology. Diagnosis of hypertension among those with no history of hypertension in our study was based on a single BP measurement. A sensitivity analysis suggests that this approach could inflate the crude prevalence by about $5.4 \%$ and $4.6 \%$ among those not known to have hypertension prior to the survey and at the total population level, respectively [10]. Nevertheless, even after accounting for this possible effect, our estimates would still be within sampling variation of the figures previously reported in this setting.

The strengths of this study include the large sample of the general population and the rigorous collection of various lifestyle factors, medical data, and blood pressure measurements by trained medical personnel according to standardized protocols. In addition, our sampling approach provides evidence that simple announcements through mass media can attract from the community a large number of individuals at risk of undiagnosed hypertension.

\section{Conclusion}

In this survey in Mafia Island, almost half of the participants had moderate to severe hypertension, most of whom were unrecognized. Together with that, those who were aware of their disease were also assessed for control of the situation and this study showed their control was not adequate. This is very alarming and therefore shows a need to raise awareness and availability of screening, treating, and followup. Furthermore, this study can act as a baseline for more studies to be undertaken and more evidence to be gathered.

\section{Disclosure}

Part of this paper was presented at the Muhimbili University of Health and Allied sciences (MUHAS) scientific conference [16].

\section{Competing Interests}

The authors declare they have no competing interests or any possible conflicts of interest regarding the publication of this paper.

\section{Authors' Contributions}

M. S. Muhamedhussein and Z. I. Nagri contributed equally to this work. They worked on literature review, designed methodology, collected data, and performed analysis after data entry. K. P. Manji offered expert advice when it came to methodology, participated in data collection, and helped design the discussion and conclusion.

\section{Acknowledgments}

The authors would like to thank Bilal Muslim Mission of Tanzania, which organized the eye and medical camp, for its 
utmost support. Together with that, heartfelt thanks go to the sponsor of the camp Beta Charitable of United Kingdom. Appreciation also goes to the research assistants and fellow medical doctors including Dr. Fatemazahra Karim and Dr. Maryam Khimji who put their invaluable effort in the data collection.

\section{References}

[1] D. O. Abegunde, C. D. Mathers, T. Adam, M. Ortegon, and K. Strong, "The burden and costs of chronic diseases in lowincome and middle-income countries," The Lancet, vol. 370, no. 9603, pp. 1929-1938, 2007.

[2] P. M. Kearney, M. Whelton, K. Reynolds, P. Muntner, P. K. Whelton, and J. He, "Global burden of hypertension: analysis of worldwide data," The Lancet, vol. 365, no. 9455, pp. 217-223, 2005.

[3] K. Tibazarwa, L. Ntyintyane, K. Sliwa et al., "A time bomb of cardiovascular risk factors in South Africa: results from the Heart of Soweto Study 'Heart Awareness Days,' International Journal of Cardiology, vol. 132, no. 2, pp. 233-239, 2009.

[4] S. Stewart, D. Wilkinson, C. Hansen et al., "Predominance of heart failure in the heart of Soweto study cohort: emerging challenges for urban African communities," Circulation, vol.118, no. 23, pp. 2360-2367, 2008.

[5] C. D. Mathers and D. Loncar, "Projections of global mortality and burden of disease from 2002 to 2030," PLoS Medicine, vol. 3, no. 11, article e442, 2006.

[6] S. Kingue, C. N. Ngoe, A. P. Menanga et al., "Prevalence and risk factors of hypertension in urban areas of Cameroon: A Nationwide Population-Based Cross-Sectional Study," Journal of Clinical Hypertension, vol. 17, no. 10, pp. 819-824, 2015.

[7] K. Steyn, T. A. Gaziano, D. Bradshaw, R. Laubscher, and J. Fourie, "Hypertension in South African adults: results from the Demographic and Health survey, 1998," Journal of Hypertension, vol. 19, no. 10, pp. 1717-1725, 2001.

[8] R. Edwards, N. Unwin, F. Mugusi et al., "Hypertension prevalence and care in an urban and rural area of Tanzania," Journal of Hypertension, vol. 18, no. 2, pp. 145-152, 2000.

[9] C. Agyemang, M. A. Bruijnzeels, and E. Owusu-Dabo, "Factors associated with hypertension awareness, treatment, and control in Ghana, West Africa," Journal of Human Hypertension, vol. 20, no. 1, pp. 67-71, 2006.

[10] A. Dzudie, A. P. Kengne, W. F. T. Muna et al., "Prevalence, awareness, treatment and control of hypertension in a self-selected sub-Saharan African urban population: a crosssectional study," BMJ Open, vol. 2, no. 4, Article ID e001217, 2012.

[11] http://en.wikipedia.org/wiki/Mafia_Island.

[12] http://mafia-island-tanzania.gold.ac.uk.

[13] A. V. Chobanian, G. L. Bakris, H. R. Black et al., "The Seventh report of the Joint National Committee on Prevention, detection, evaluation and treatment of high blood pressure," The Journal of the American Medical Association, vol. 289, no. 19, pp. 2560-2571, 2003.

[14] World Health Organization (WHO), Obesity: Preventing and Managing the Global Epidemic, 2000, Reprinted in 2004.

[15] G. Mancia, G. De-Backer, A. Dominiczak et al., "Guidelines for the management of arterial hypertension: the Task Force for the Management of Arterial Hypertension of the European Society of Hypertension (ESH) and of the European Society of
Cardiology (ESC)," Journal of Hypertension, vol. 25, pp. 11051187, 2007.

[16] http://www.muhas.ac.tz/Advertisements/Scientific_Conference/ MUHAS\%20CONFERENCE\%20FINAL\%20TIME\%20TABLE .pdf. 


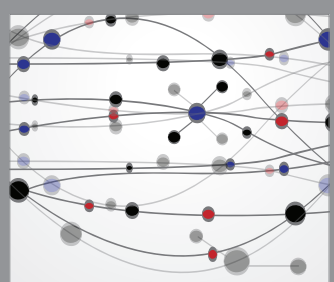

The Scientific World Journal
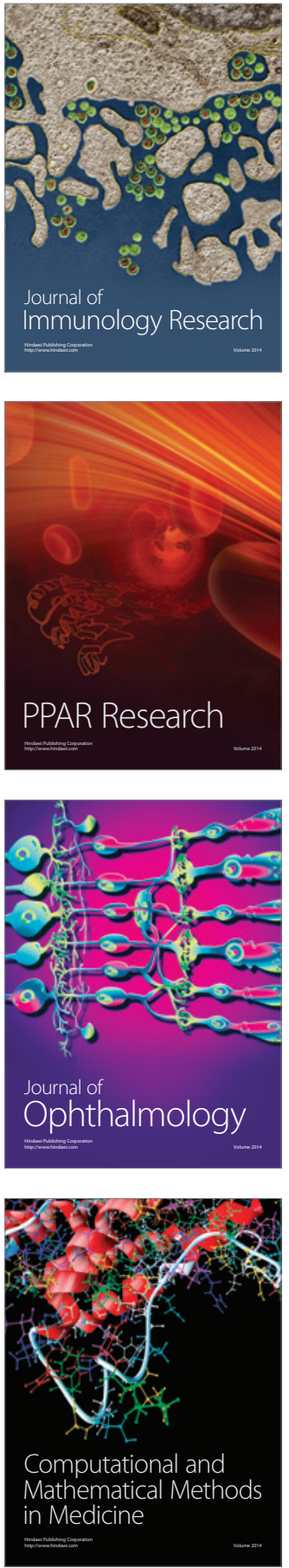

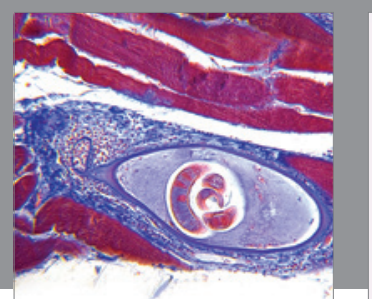

Gastroenterology Research and Practice

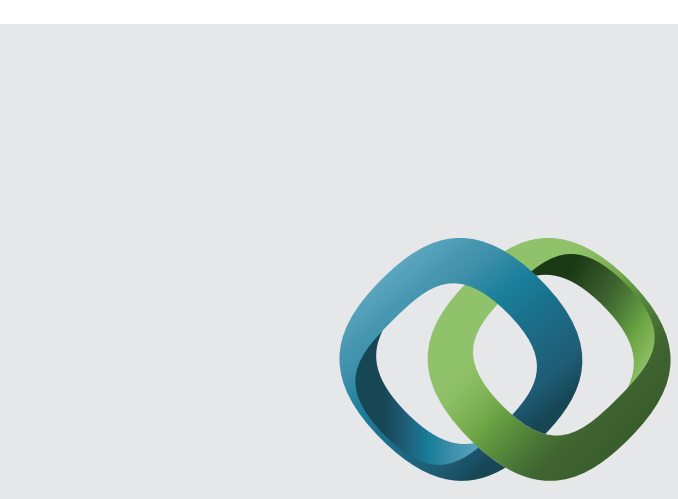

\section{Hindawi}

Submit your manuscripts at

http://www.hindawi.com
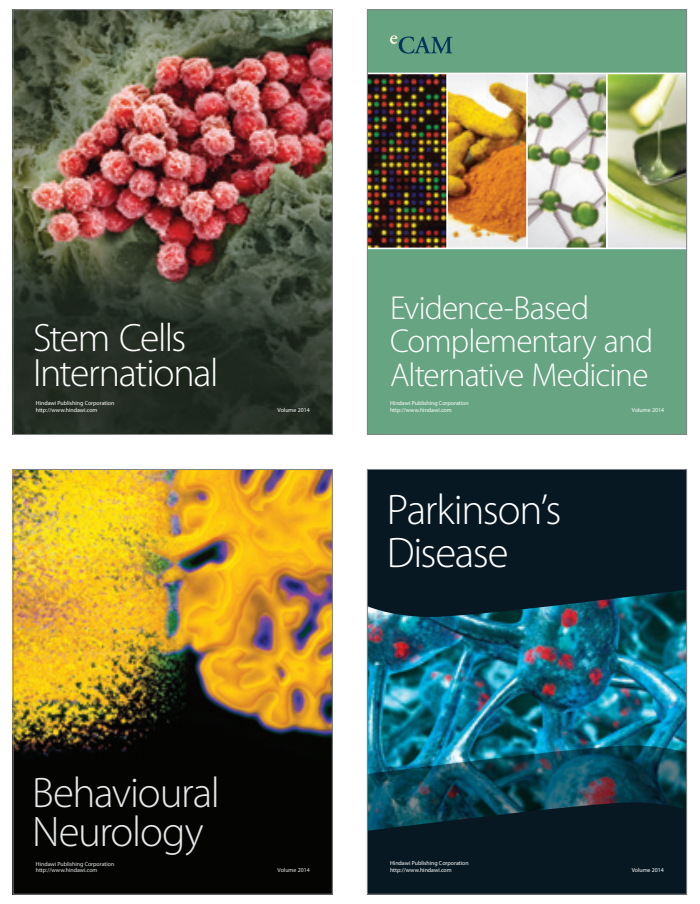
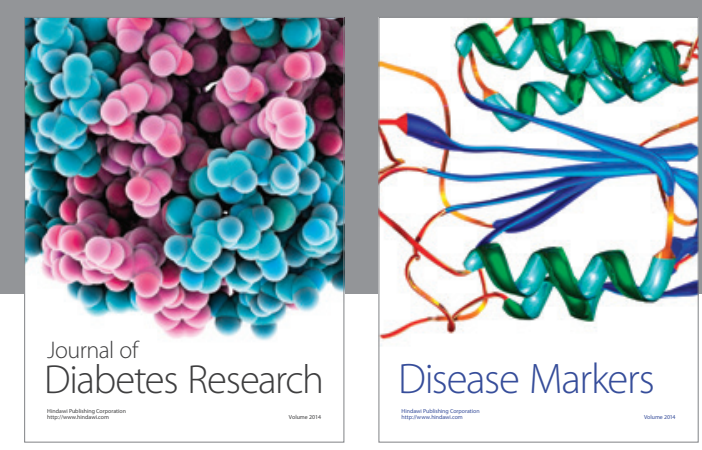

Disease Markers
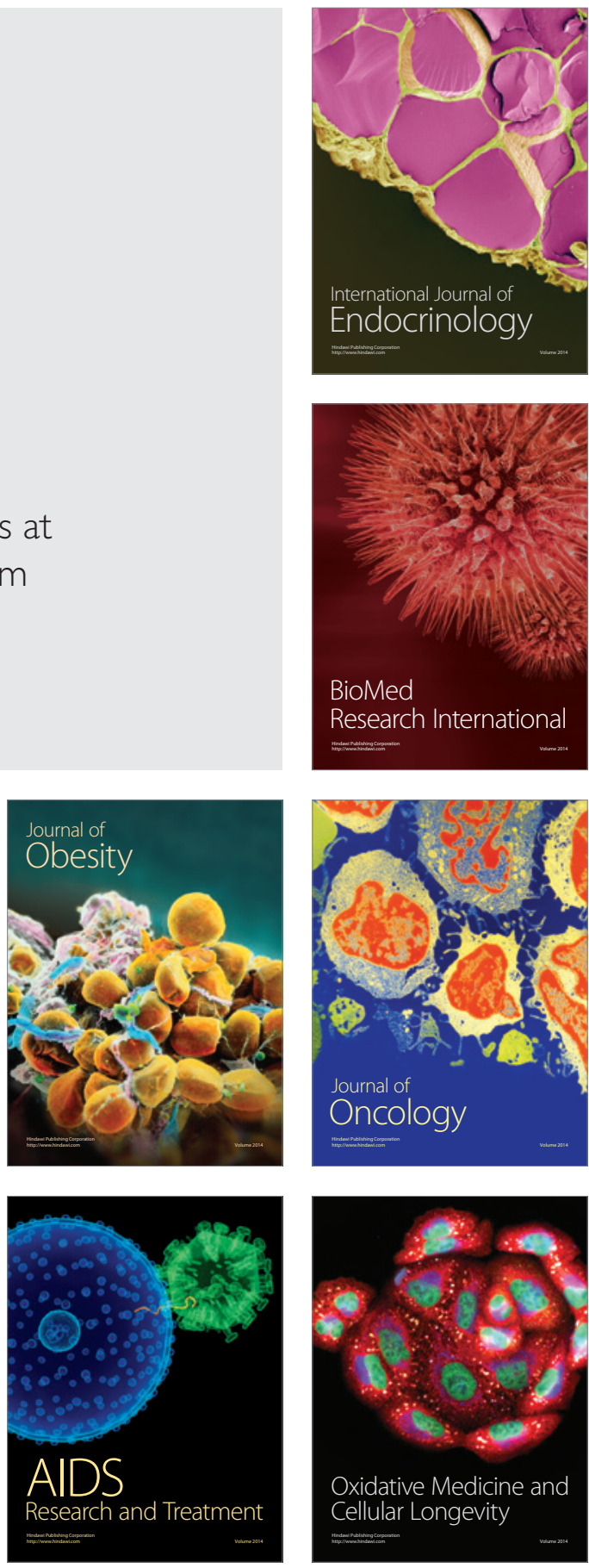